\title{
JAK2 Inhibitor AZD1480
}

National Cancer Institute

\section{Source}

National Cancer Institute. AAK2 Inhibitor AZD1480. NCI Thesaurus. Code C91394.

An orally bioavailable inhibitor of Janus-associated kinase 2 (JAK2) with potential antineoplastic activity. JAK2 inhibitor AZD1480 inhibits JAK2 activation, leading to the inhibition of the JAK/STAT (signal transducer and activator of transcription) signaling including activation of STAT3. This may lead to induction of tumor cell apoptosis and a decrease in cellular proliferation. JAK2, often upregulated or mutated in a variety of cancer cells, mediates STAT3 activation and plays a key role in tumor cell proliferation and survival. 